in haematology or oncology or in bone marrow transplantation centres. Thus, although the specifics of bone marrow transplantation are crucial for transplant physicians, they are unlikely to be of interest, or importance, to non-specialists.

With regard to Simon A J Rule and colleagues' final comment, although Aberdeen is a small transplant centre our experience in marrow transplantation is not limited to this single institution.

RICHARD L SOUTAR Senior registra DEREK J KING

Department of Haematology,
Aberdeen Royal Hospitals NHS Trust, Consultant haematologist

Aberdeen AB9 2ZD

\section{Acute dissection of the thoracic aorta}

\section{Transoesophageal echocardiography has} wider uses

EDrToR,-Adrian P Banning and colleagues suggest that transoesophageal echocardiography is the investigation of choice in the diagnosis of acute dissection of the thoracic aorta because it can be performed rapidly and is minimally invasive. ${ }^{1}$ It also can be performed in the casualty department, intensive care unit, or operating theatre, so that an unstable patient does not have to be transferred to a radiology suite. For these reasons it should also be considered in the acute investigation of patients who have suffered blunt chest trauma.

Transoesophageal echocardiography has been shown to be superior to transthoracic echocardiography in acutely diagnosing cardiac trauma such as tamponade, acute valve lesions, pericardial effusions, myocardial contusion, and acute traumatic thoracic aortic dissections. ${ }^{2-4}$ Other investigations used to diagnose cardiac injuries and injuries to major thoracic vessels, such as chest radiography and electrocardiography, are extremely non-specific, and important traumatic cardiac lesions are missed at surgery in a tenth of cases." The benefit of transoesophageal echocardiography in these situations is indisputable. Unless it is requested acutely and a capable operator is available, however, the benefits cannot be enjoyed. Awareness that transoesophageal echocardiography can be used as a diagnostic tool in patients with acute trauma should be promoted among those who manage these patients-casualty staff, surgeons, and anaesthetists. As transoesophageal echocardiography becomes more widespread, hopefully the availability of trained staff able to provide an acute diagnostic service will increase.

Paediatric Intensive Care Unit,

NJ KENNEDY Senior registrar

Princess Margaret Hospital For Children,

Subiaco, 6008 Western Australia

Australia

1 Banning AP, Ruttley MST, Musumeci F, Fraser AG. Acute dissection of the thoracic aorta. BMF 1995;310:72-3. dissection

2 Shapiro MJ, Yanofsky SD, Trapp J, Durham RM, Labovitz A Sear JE, et al. Cardiovascular evaluation in blunt chest traum using transoesophageal echocardiography (TEE). $\mathcal{f}$ Trauma 1991;31:835-40.

3 Porembka DT, Hoit BD. Transesophageal echocardiography in the intensive care patient. Crit Care Med 1991;19:826-35.

4 Porembka DT, Johnson DJ, Hoit BD, Reising J III, Davis K Jr, Koutlas T. Penetrating cardiac trauma: A role for transesophageal echocardiography. Anesth Analg 1993;77:1275-7.

5 Clements F. The role of transoesophageal echocardiography in patients with chest trauma. Anesth Analg 1993;77:1089-90.

\section{Magnetic resonance imaging is useful}

EdrToR,-We take issue with Adrian P Banning and colleagues' opinion that transoesophageal echocardiography is the investigation of choice in acute dissection of the thoracic aorta. ${ }^{1}$ We agree that early and accurate diagnosis is essential if patients are to be offered the benefits of surgery for a type A dissection. To this end patients should be transferred rapidly to a regional cardiothoracic unit, where a multidisciplinary team is available. After stabilisation in a high care environment, transthoracic echocardiography should be performed and, simultaneously, the results of all previous imaging studies should be thoroughly reviewed; these studies may include serial chest radiography and contrast enhanced computed tomography. If at this time the consensus of radiological and cardiological opinion is that a type A aortic dissection has occurred then emergency surgery should be planned. If the patient is unstable with signs suggesting aortic incompetence or pericardial effusion then transoesophageal echocardiography should be performed immediately.

In all other stable patients we have proceeded to emergency magnetic resonance imaging of the heart and aorta. We have examined more than 60 patients, of whom one third had type $A$ and one third had type $B$ dissections. The magnetic resonance imaging unit is within three floors and $100 \mathrm{~m}$ of the cardiothoracic unit. The journey and movement were well tolerated by most patients, with examination times of around 45 minutes. There is no requirement for an injection and no discomfort, particularly gagging, that could cause unstable blood pressure and no radiation hazard.

Magnetic resonance imaging can show all the thoracic anatomy that is pertinent to dissection, particularly the aortic wall and lumen, myocardial contractility, valve competence, and pericardial effusion. ${ }^{2}$ Moreover, objective interpretation of the image is much less dependent on the skill and experience of the operator than is interpretation of an echocardiogram.

In summary, we believe that emergency magnetic resonance imaging provides the most comprehensive and accurate assessment of a patient with a putative diagnosis of acute aortic dissection.

$\begin{array}{rr}\text { I A SIMPSON } & \text { D J DELANY } \\ \text { Consultant cardiologist } & \text { Consultant radiologist } \\ \text { S A LIVESEY } & \text { B C OGILVIE } \\ \text { Consultant cardiac surgeon } & \text { Consultant radiologist }\end{array}$

Wessex Cardiothoracic Centre,

Southampton University Hospitals Trust,

Southampton SO16 6YD

1 Banning AP, Ruttley MST, Musumeci F, Fraser AG. Acute dissection of the thoracic aorta. BMF 1995;310:72-3. (14 January.)

2 Nienamber CA, von Kodolitsch Y, Nicolas V, Siglow V, Piepho A, Brockhoff $\mathrm{C}$, et al. The diagnosis of thoracic aortic dissection by non-invasive imaging procedures. $N$ Engl $\mathcal{F} \mathrm{Med}$ 1993;328:1-9.

\section{Esmolol is safer than and as effective as labetalol}

EDIToR,-Adrian P Banning and colleagues state that labetalol is the drug of choice to control arterial pressure in patients with suspected dissection of the thoracic aorta. ${ }^{1}$ Labetalol is an appropriate hypotensive agent in certain circumstances but is disadvantaged by its relatively long half life (3-5 hours). Its use in unstable aortic conditions such as acute dissection and traumatic injury could lead to considerable difficulty in the management of hypotension should appreciable bleeding occur, particularly if transfer to a remote cardiothoracic unit is necessary.

Esmolol is a selective $\beta_{1}$ receptor antagonist with an ultrashort duration of action, having distribution and elimination half lives of 2 and 9 minutes respectively. With a loading dose followed by infusion, steady state plasma concentrations can be achieved within five minutes, producing a dose dependent reduction in heart rate and arterial pressure that can be easily titrated. The drug is metabolised by red cell esterases and is independent of renal and hepatic routes for elimination.

The pharmacological characteristics of esmolol suggest that it can control hypertension as effectively as labetalol with a greater margin of safety. It has been used successfully to control arterial pressure in a variety of conditions, including thoracic aortic vascular disease,${ }^{34}$ and should be regarded as an alternative in all such cases when there is a risk of haemodynamic instability. Furthermore, it can be safely continued, once a definitive diagnosis has been made, to facilitate accurate and prompt titration of the perioperative haemodynamic stresses that will occur should anaesthesia and surgery become necessary.

B O'CONNOR Lecturer in anaesthesia J B LUNTLEY

Royal Hallamshire Hospital, Senior registrar in anaesthesia

Sheffield S10 2JF

1 Banning AP, Ruttley MST, Musumeci F, Fraser AG. Acute dissection of the thoracic aorta. BMF 1995;310:72-3. (14 January.)

2 Sum CY, Yacobi A, Kartzinel R, Stampfli H, Davis CS, Lai C-M. Kinetics of esmolol, an ultra-short-acting beta-blocker, and of its major metabolite. Clin Pharmacol Ther 1983;34:427-43.

3 Fenner SG, Mahoney A, Cashman JN. Repair of traumatic transection of the thoracic aorta: esmolol for intraoperative control of arterial pressure. Br $\mathcal{F}$ Anaesth 1991;67:483-7.

4 Devanand DP, Malitz S, Sackeim HA. ECT in a patient with aortic aneurysm. $f$ Clin Psychiatry 1990;51:255-6.

\section{Garlic's protective effect}

EDITOR,-We note with interest Minerva's report that garlic may protect the carotid arteries.' It has, of course, been known for many years that garlic protects the jugular veins. ${ }^{2}$

ANDY SIMPSON Registrar

JIM BODDINGTON Senior house office

Accident and Emergency Department,

Sheffield Children's Hospital,

Sheffield S10 2TH

1 Minerva. BMf 1995;310:680. (11 March.)

2 Stoker B. Dracula. London: Wordsworth Classics, 1993.

\section{Lottery stress disorder}

EDITOR,-I wish to report the appearance of a condition that has been seen in our psychiatric clinic over the past few weeks. It is not known to have occurred previously in Britain, although we suspect that it has been prevalent in other countries for some time.

The patients who have presented have shown an initially intense anticipatory anxiety, which has built throughout the week to reach a characteristic peak in the early evening on Saturday. This anticipatory anxiety is often accompanied by unrealistic optimism and grandiose ideas. Despite the unrealistic odds of millions to one the subject experiences the delusional belief that great riches are about to befall him or her (the condition seems to have no sex bias) and, on the basis of this belief, makes extraordinary, and often comprehensive, spending plans. Inevitably, at peak intensity on Saturday evenings these features give way to rapid deflation of mood and feelings of hopelessness, and relief is often sought through ingestion of excess alcohol. At the start of the week recovery has begun to set in, although, characteristically, the pattern repeats itself over the coming week.

We have noted several cases of this compulsive behaviour in the clinic and are at a loss to know how to help the sufferers. We have given the condition the provisional name of lottery stress disorder or LSD, and would be interested to hear whether other clinicians have seen similar cases.

ROBERT HUNTER

Gartnavel Royal Hospital

Consultant psychiatrist

Glasgow G12 0XH 